\title{
Mejora en la interpretación de las imágenes proporcionadas por la lámpara de hendidura mediante la visualización 3D
}

\author{
L. Remóna, M.C. Marcellána , F.J. Ávila a , J. Ares ${ }^{a}$, V. Collados ${ }^{a}$, N. Elía ${ }^{a}$, S. Perchés ${ }^{a}$, \\ I. Altemira, C. Lopez de la Fuente. \\ ${ }^{a}$ Universidad de Zaragoza. Departamento de Física Aplicada. 50009 Zaragoza
}

\begin{abstract}
In this work we present a new methodology to create $3 D$ images through the simple images obtained with the slit lamp. The proposed methodology is aimed at students of Optics and Optometry and consists of: 1) Acquisition of images with each eyepiece of the slit-lamp, 2) Fusion of the images obtained with a software developed in MATLAB GUI (Graphical User Interface) and 3) Visualization of the $3 D$ images with the red/green glasses or polarized filters. A didactic level is intended to achieve an improvement in the interpretation of the obtained images with the new methodology. To assess the effectiveness of the technique, the obtained marks in the last two years are compared with those registered in the 2018-2019 academic year in the subject "Optometry Laboratory". As an example, some $3 D$ images of different ocular structures with different techniques are shown. This new methodology could be useful for any area that teaches how to use instruments with binocular microscopes.
\end{abstract}

Keywords: slit-lamp, visualization 3D, depth perception

\section{Resumen}

En este trabajo se presenta una nueva metodología para la creación de imágenes $3 D$ a través de las imágenes sencillas obtenidas con la lámpara de hendidura. La metodología propuesta esta dirigida a estudiantes de Óptica y Optometría y consiste en: 1) Adquisición de imágenes con cada uno de los oculares de la lámpara de hendidura, 2) Composición de las imágenes $3 D$ con un software desarrollado en MATLAB GUI (Interfaz Gráfica de Usuario y 3) Visualización de las imágenes $3 D$ mediante el uso de gafas rojo/verde o filtros polarizados. A nivel didáctico se pretende conseguir una mejora en la interpretación de las imágenes obtenidas con la nueva metodología. Para valorar la eficacia de la técnica se comparan las notas obtenidas en los dos últimos años con las registradas en el curso académico 2018-2019 en la asignatura de "Laboratorio de Optometría". A modo de ejemplo, se muestran algunas imágenes $3 D$ de diferentes estructuras oculares con distintas técnicas. Esta nueva metodología podría ser de utilidad para cualquier área que enseñe a emplear instrumentos con microscopios binoculares.

Palabras clave: lámpara de hendidura, percepción de profundidad, visualización $3 D$. 


\section{Introducción}

La exploración del segmento anterior del ojo es una parte importante del examen general de la salud ocular. Para ello, se utiliza el biomicroscopio, también conocido como lámpara de hendidura, que combina básicamente un sistema de iluminación y un estereomicroscópico que permite la observación de las distintas estructuras que componen el globo ocular con una magnificación de 6 a 40 aumentos. El examen con lámpara de hendidura permite estudiar estructuras oculares tales como párpados, conjuntiva, cornea, iris, cámara anterior y cristalino (González-Cavada, 2015). Además la lámpara de hendidura es útil para la adaptación de lentes de contacto y el seguimiento posterior de la adaptación (Sulley, 2013).

Su amplio rango de magnificación, su sistema de iluminación variable y la posibilidad de examinar bajo diferentes ángulos de observación permite desarrollar un amplio número de técnicas para observar distintas estructuras oculares (Jones, 1996), (Chauhan, 1999). En la Figura 1 se observan algunas de las técnicas utilizadas para la visualización de diferentes estructuras oculares, concretamente la reflexión especular que permite la visualización de las células endoteliales y la dispersión escleral que permite la detección de opacidades corneales (Perchés, 2015).

Antes de su utilización es necesario realizar unos ajustes previos en el sistema de observación tales como el enfoque de los oculares o el ajuste de la distancia interpupilar, parámetros cruciales para realizar el examen en condiciones binoculares. La binocularidad durante el examen permite por una parte la percepción de relieve de las distintas estructuras oculares (percepción de profundidad), aumentando la precisión de enfoque y por otra parte, facilita la correcta interpretación de las imágenes para llegar a un diagnóstico final. La complejididad y versatilidad de los brazos de iluminación y observación, hacen que el aprendizaje para su correcta utilización no sea del todo sencillo (Veys, 2016). Además la interpretación correcta de las imágenes no es tarea fácil y depende en gran medida de la experiencia previa del examinador (Painter, 2015).

La lámpara de hendidura se utiliza en las asignaturas de segundo curso de "Laboratorio de Optometría" y de tercer curso de "Contactología" del Grado de Óptica y Optometría de la Universidad de Zaragoza. Actualmente, para su aprenzidaje se emplean sistemas de vídeo digital para que los alumnos puedan observar lo que el profesor ve mientras realiza una técnica de observación concreta (Gargallo, 2014). Sin embargo, la cámara digital proporciona una imagen unidimensional, frente a la imagen tridimensional que se ve a través del sistema de observación. Por lo tanto, la experiencia visual de los alumnos no es fiel con lo que el profesor está visualizando. La ausencia de dicha información 3D dificulta seriamente la interpretación de las imágenes adquiridas. Por ese motivo, en este trabajo se presenta una nueva metodología que permite la creación de contenidos 3D para su posterior visualización por parte de los estudiantes. Con esta nueva técnica se pretende mejorar la interpretación de las imágenes frente a las imágenes unidimensionales obtenidas con los sistemas de captura utilizados actualmente. En la evaluación de las citadas asignaturas existe una prueba práctica específica que valora la capacidad de manejo de la lámpara de 
hendidura así como un examen tipo test donde se valorala capacidad de los alumnos para interpretar las imágenes obtenidas con la lámpara. Como método de valoración de la eficacia de la metodología propuesta se comparan las calificaciones obtenidas por los alumnos en los dos últimos años con las registradas en el curso 2018-2019. La metodología propuesta va dirigida a estudiantes del Grado de Óptica y Optometría de la Universidad de Zaragoza. Concretamente se utilizará en las asignaturas de "Laboratorio de Optometría" y de "Contactología". En este trabajo, únicamente se han comparado las calificaciones obtenidas en la asignatura de "Laboratorio de Optometría".

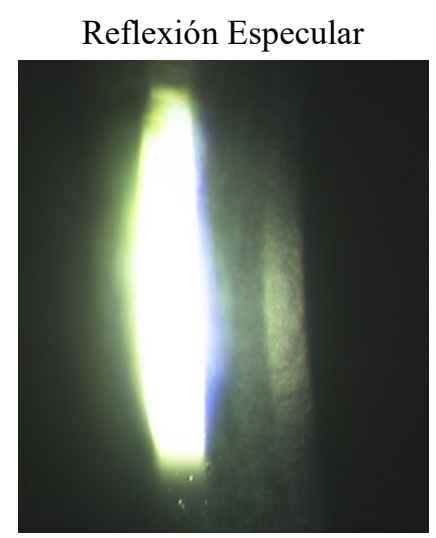

REFLEXIÓN ESPECULAR

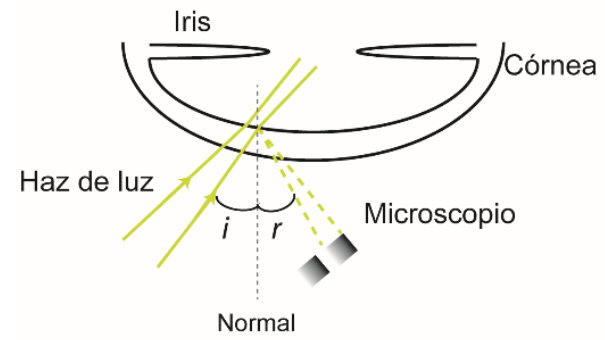

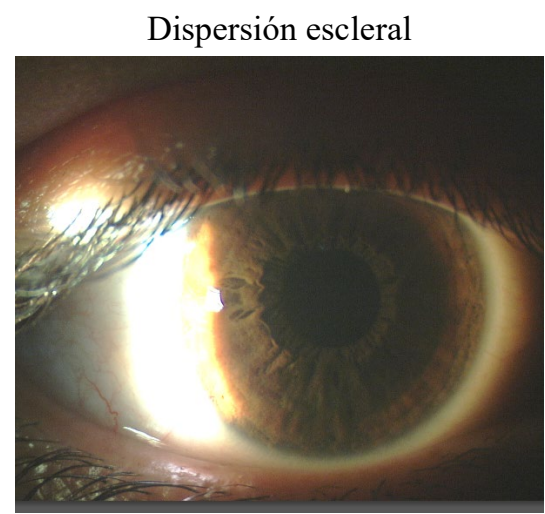

DISPERSIÓN ESCLERAL

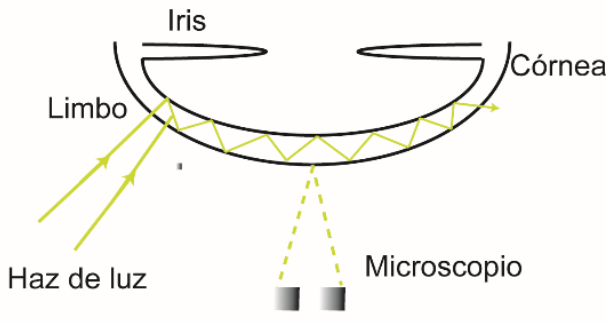

Fig. 1 Izquierda Arriba: Imagen de las células endoteliales mediante la técnica de reflexión especular. Izquierda Abajo: Esquema de la posición del sistema de iluminación y observación en la reflexión especular

Derecha Arriba: Imagen de la córnea mediante la técnica de dispersión escleral. Derecha Abajo: Esquema de la posición del sistema de iluminación y observación en la dispersión escleral.

\section{Objetivos}

Los objetivos principales de este trabajo son:

1) El desarrollo de una nueva metodología que permita la creación de contenidos $3 \mathrm{D}$ a partir de las imágenes unidimensionales obtenidas con la lámpara de hendidura.

2) A nivel didáctico se pretende conseguir una mejora en la interpretación de las imágenes obtenidas con la nueva metodología frente a las obtenidas con cámara digital que proporciona imágenes unidimensional. Para valorar la eficacia de la 
metodología propuesta se comparan las calificaciones obtenidas por los alumnos en los últimos años con las registradas en el curso 2018-2019 en la asignatura de "Laboratorio de Optometría".

\section{Desarrollo de la innovación}

Para llevar a cabo los objetivos principales del trabajo se han realizado dos actividades:

1) Creación de contenidos $3 \mathrm{D}$ mediante lámpara de hendidura. Durante las sesiones prácticas de aprendizaje de lámpara de hendidura, mediante el uso de adaptadores para acoplar el teléfono móvil a la lámpara de hendidura, los alumnos deberán crear contenidos 3D que reflejen alguna técnica o escenario que el profesor proponga.

2) Uso de los contenidos $3 \mathrm{D}$ durante las actividades de aprendizaje de interpretación de las imágenes. Los alumnos usarán contenidos registrados anteriormente u otros generados por los propios profesores de las asignaturas, con el objetivo de comparar la interpretación de las imágenes obtenidas con esta técnica frente a la obtenida con registro digital (imagen unidimensional).

La metodología propuesta para llevar a cabo la actividad 1 es la que se describe a continuación:

1) Adquisición y registro digital de vídeo e imagen para crear contenidos 3D. Para ello, se acoplan a los oculares del sistema de observación dos móviles de las mismas características (Samsung S4) mediante un soporte y se registran dos imágenes de la estructura ocular que se quiere estudiar o visualizar. En la Figura 2 se muestra el sistema utilizado para la toma de imágenes.

2) Composición de la imagen o vídeo en formato de visualización 3D. En la Figura 3 se muestra el prodecimiento utilizado para la composición de la imagen 3D a partir de las imágenes sencillas obtenidas con cada móvil. En primer lugar, las imágenes obtenidas con cada uno de los móviles (véase Figura 3a) se exportan a un software de procesado de imagen (Matlab, MathWorks ${ }^{\circledR}$ ) para ser transformadas a escala de grises (véase Figura 3b). A continuación, se aplican filtros rojo y verde a las imágenes correspondientes al ocular del OD y OI, respectivamente (Figura 3c). Posteriormente se realiza la composición (fusión) de las imágenes roja y verde obteniendo una imagen final que puede ser visualizada en 3D (Figura 3d) con un correcto sistema de visualización (gafas rojo-verde).

El mismo prodecimiento puede ser utilizado para la creación de imágenes 3D polarizadas para su posterior visualización con filtros polarizados. 


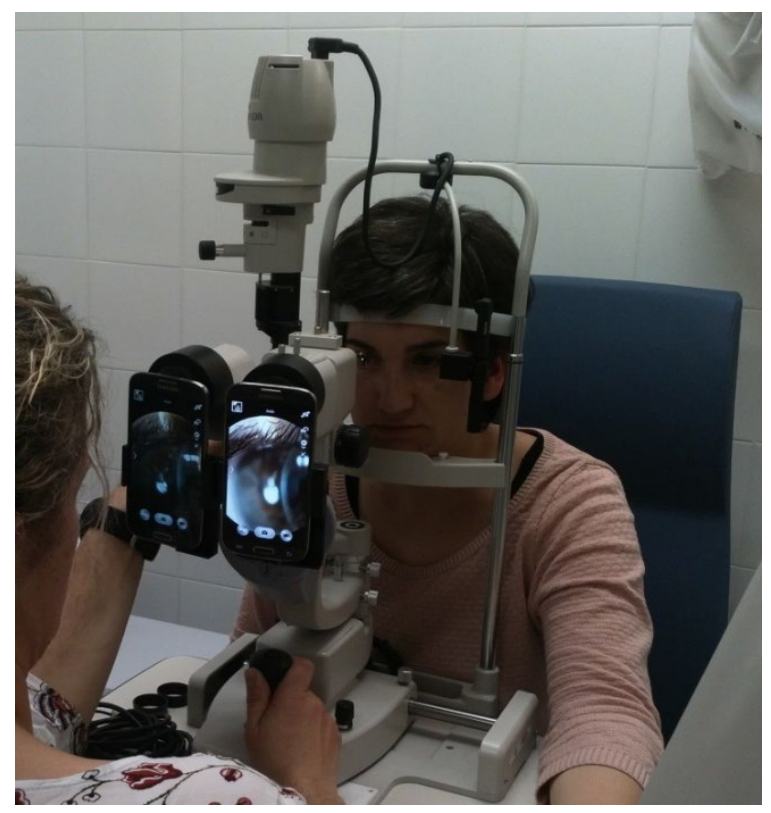

Fig. 2 Lámpara de hendidura donde en el sistema de observación se han acoplado dos móviles uno en cada ocular para la toma de imágenes sencillas.

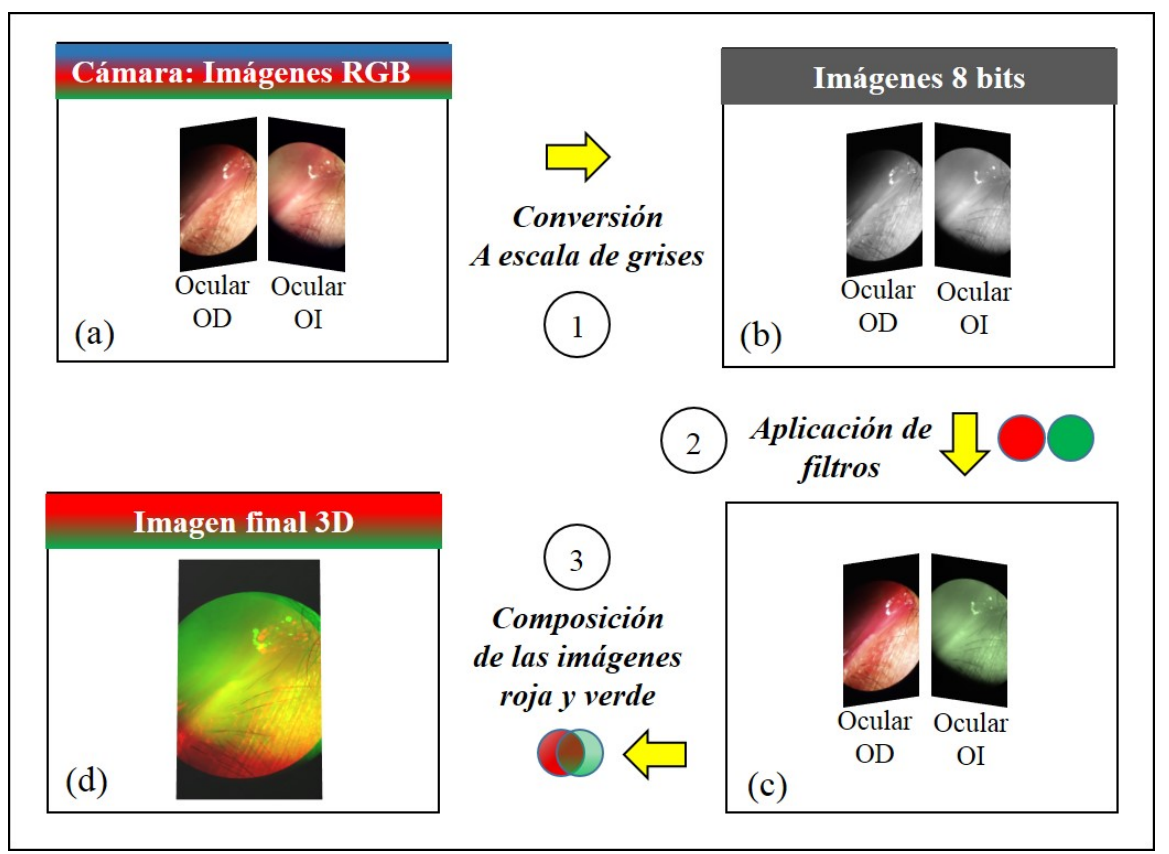

Fig. 3 Procedimiento para la composición de la imagen 3D a partir de las imágenes sencillas obtenidas con cada móvil. Para más detalle véase el texto. 
La actividad 2 consiste en la visualización e interpretación de las imágenes 3D creadas en la actividad 1. En la Figura 4 se observa a un grupo de estudiantes durante una sesión práctica de la asignatura "Laboratorio de Optometría" visualizando una imagen 3D con el uso de gafas con filtros rojo/verde. Los alumnos en esta sesión práctica observaron distintas imágenes $3 \mathrm{D}$ creadas por ellos mismos o generadas por los propios profesores de la asignatura, con el fin de interpretar correctamente las imágenes y poder determinar algún hallazgo significativo en las mismas tales como cataratas, opacidades corneales, etc.
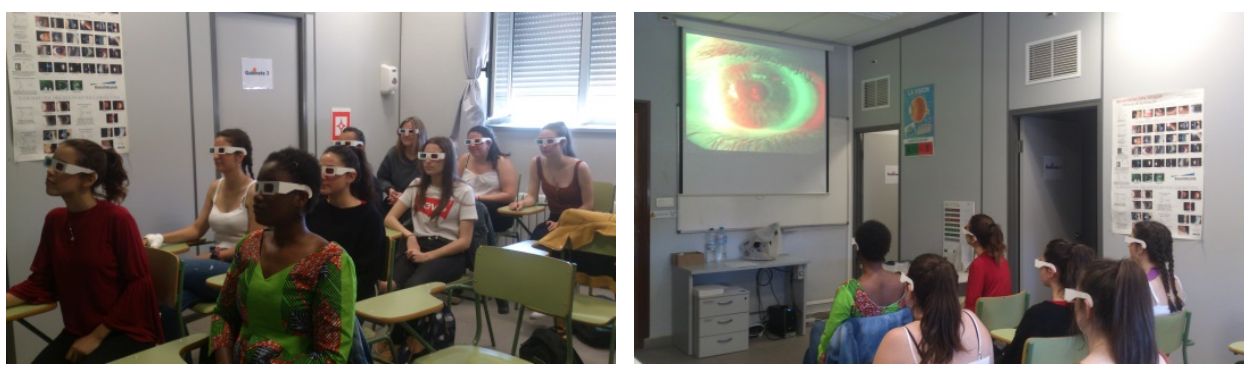

Fig. 4 Grupo de estudiantes en una sesión práctica de la asignatura "Laboratorio de Optometría”, visualizando una imagen $3 D$ previamente creada, con el uso de gafas con filtro rojo/verde.

A partir de la metodología propuesta, se han generado una batería de imágenes 3D que reflejan la mayoría de las técnicas y prodecimientos que se pueden llevar a cabo con la lámpara de hendidura para un correcto examen del segmento anterior del globo ocular.

\section{Resultados}

En primer lugar, se muestran algunas imágenes de distintas estructuras oculares obtenidas con la metodología propuesta. En la Figura 5 se muestra la técnica de la dispersión escleral que permite la detección de opacidades corneales. En la parte de la izquierda se muestran las imágenes obtenidas con cada uno de los dos móviles colocados en los oculares del sistema de observación y en la parte de la derecha se muestra la composición final (obtenida con el prodecimiento descrito en la Figura 3) para su posterior visualización con el uso de gafas con filtros rojo/verde. En la Figura 6 se muestra la composición final de la primera cara del cristalino con la técnica de sección óptica que permite la detección de cataratas. En la parte de la izquierda se muestra la imagen 3D obtenida para su visualización con el uso de gafas con filtros rojo/verde y en la parte de la derecha la imagen para su visualización con filtros polarizados. Se puede ver claramente la estructura tridimensional de la cámara anterior, con la zona iluminada de la córnea que queda por delante y el cristalino detrás del iris. 
OD

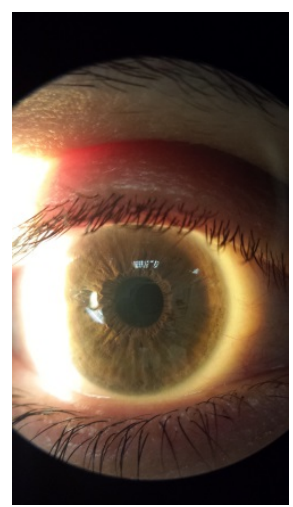

OI
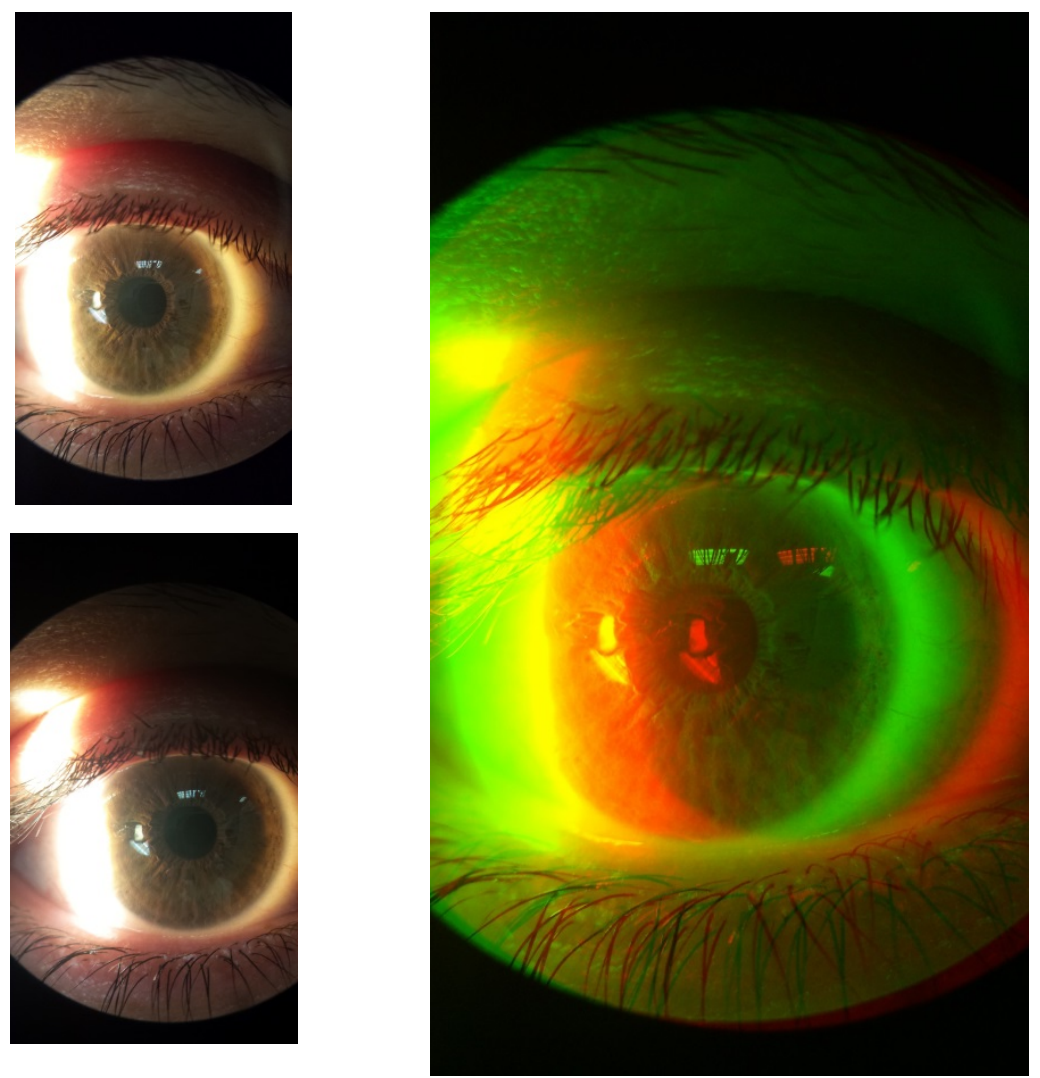

Fig. 5 Técnica dispersión escleral para la visualización de opacidades corneales. En la columna de la izquierda se muestran las imágenes sencillas obtenidas con cada uno de los móviles acoplados en los oculares. En la columna de la derecha se muestra la fusión de las imágenes roja y verde para su posterior visualización $3 D$ mediante una gafa con filtros rojo/verde. Esta imagen ha sido obtenida mediante el prodecimiento descrito en la Figura 3.

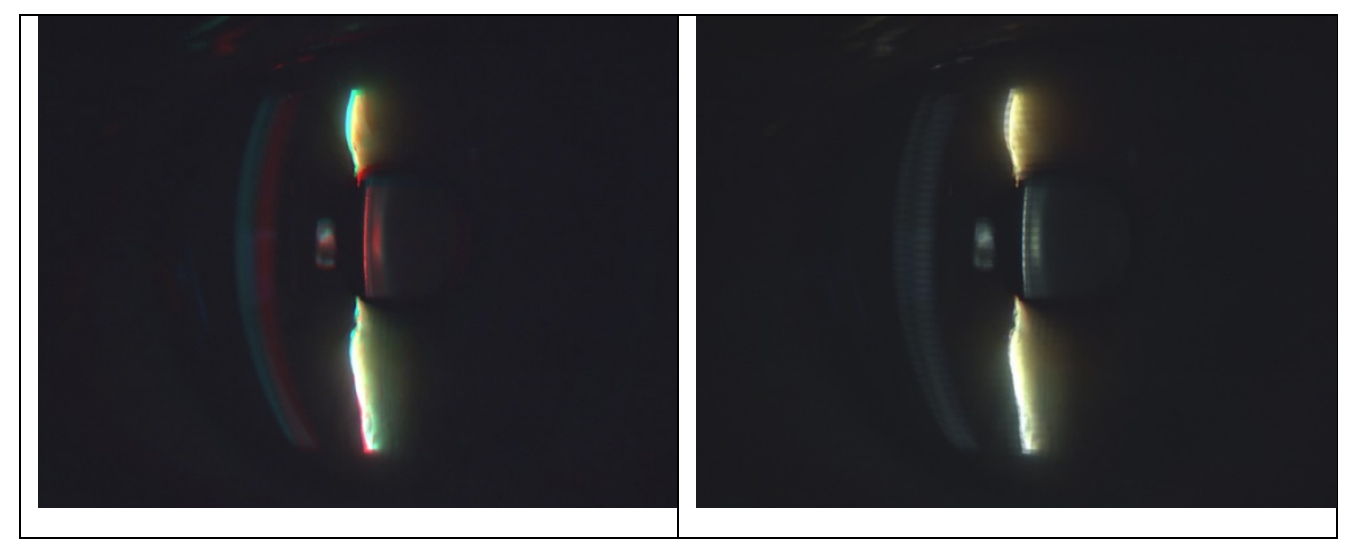

Fig. 6 Sección óptica del cristalino para la detección de cataratas. Composición final del cristalino para su visualización en 3D. Izquierda: con gafas rojo/verde. Derecha: con filtros polarizados.

En segundo lugar, para valorar la eficacia de la metodología propuesta se han comparado las calificaciones obtenidas por los alumnos en los últimos dos años con las registradas en 
el curso 2018-2019. Como se ha comentado en la introducción, en la evaluación de la asignatura de "Laboratorio de Optometría" existe una prueba práctica específica que valora la capacidad de manejo de la lámpara de hendidura. En esta parte el profesor pide la realización de una exploración completa del segmento anterior del ojo de un compañero y una técnica extra. Además como parte de la evaluación, se realiza un examen tipo test donde se muestran imágenes obtenidas con la lámpara de hendidura que los alumnos deben interpretar. En los cursos anteriores las imágenes se encontraban impresas en el propio examen. Este año durante el examen tipo test las imágenes han sido proyectadas en una pantalla de visualización de contenidos 3D mediante gafas con filtros rojo/verde. En la Figura 7 se compara la calificación media obtenida en los dos últimos años con la calificación media obtenida durante el presente curso académico con la nueva metodología para las dos partes que componen la evaluación de la asignatura. Los mismos resultados se muestran en la Tabla 1. Se observa que la diferencia de nota media para el manejo de la lámpara es de 0.83 puntos siendo la máxima para el curso académico 2018/2019 y la mínima para el curso 2017/2018. En la parte de la interpratción de las imágenes la diferencia de calificaciones es mayor siendo de 1.20 puntos donde se obtiene una media 8.89 puntos para el curso académico 2018/2019 y 7.69 puntos para el curso 2017/2018.

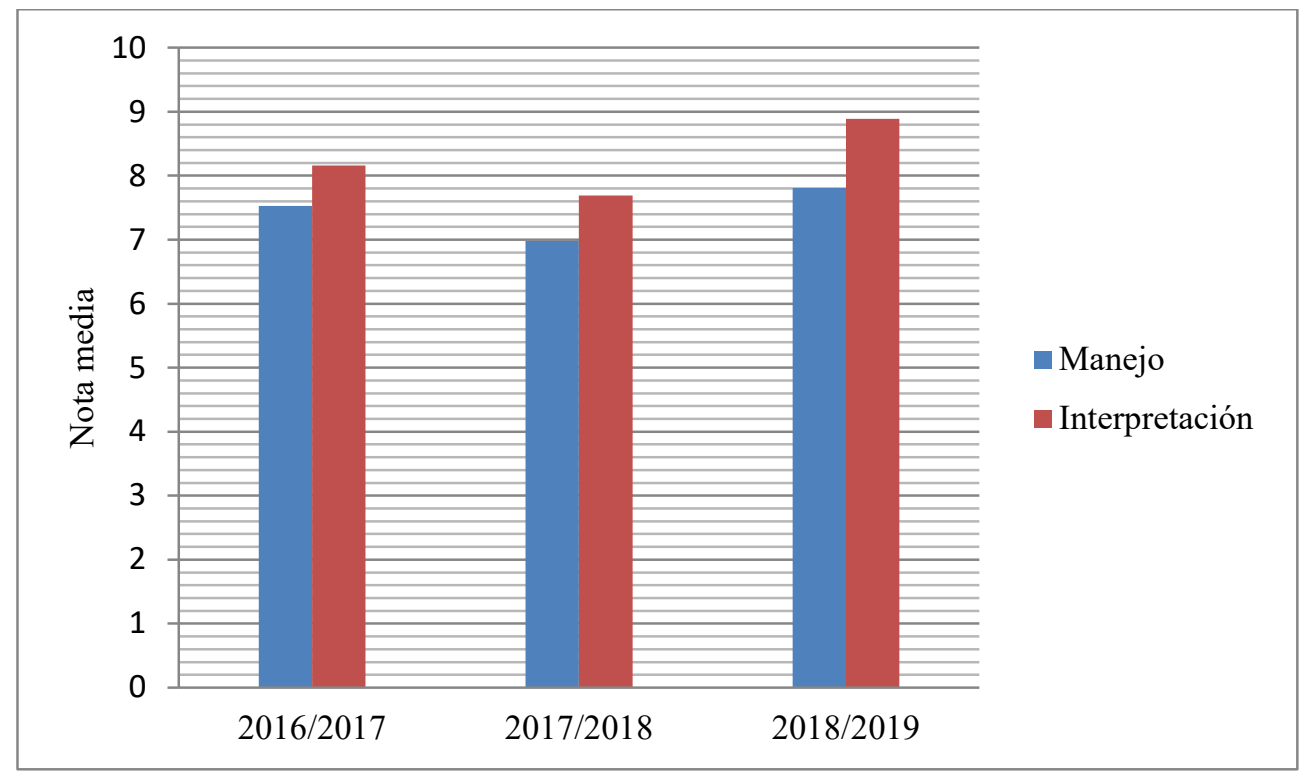

Fig. 7 Comparación de la calificación media obtenida en los dos últimos años con la calificación media obtenida durante el presente curso académico con la nueva metodología para las dos partes evaluadas (manejo e interpretación de las imágenes). 
Tabla 1. Calificación media y desviación estándar obtenida en los dos últimos años con la calificación media obtenida durante el presente curso académico con la nueva metodología

\begin{tabular}{|c|c|c|c|}
\hline & $\begin{array}{c}\mathbf{2 0 1 6} / \mathbf{2 0 1 7} \\
(49 \text { alumnos })\end{array}$ & $\begin{array}{c}\mathbf{2 0 1 7} / \mathbf{2 0 1 8} \\
(53 \text { alumnos })\end{array}$ & $\begin{array}{c}\mathbf{2 0 1 8} / \mathbf{2 0 1 8} \\
(47 \text { alumnos })\end{array}$ \\
\hline Manejo & $7,53 \pm 1.12$ & $6,98 \pm 1.17$ & $7,81 \pm 2.05$ \\
\hline Interpretación & $8,16 \pm 1.89$ & $7,69 \pm 2.17$ & $8,89 \pm 2.27$ \\
\hline
\end{tabular}

\section{Conclusiones}

La metodología propuesta permite obtener imágenes 3D a través de las imágenes unidimensionales obtenidas con la lámpara de hendidura. Los ejemplos presentados muestran que se puede utilizar para visualizar cualquier estructura ocular independientemente de la técnica empleada para ello, por lo que la técnica propuesta es muy vérsatil. Para valorar la eficacia de la técnica se han comparado las calificaciones obtenidas por los alumnos en los últimos dos años con las registradas en el curso 20182019. Se obtiene que las notas en la parte de interpretación de las imágenes son considerables mejores para el presente curso académico que la que se obtenen en cursos anteriores. Sin embargo, los resultados obtenidos en el manejo de la lámpara de hendidura son similares en los tres cursos académicos. La metodología propuesta permite la observación estereoscópica de las distintas estructuras oculares, es decir, una mejor percepción de la profundidad y relieve de las mismas, lo que hace más fácil la interpretación de las imágenes. El desarrollo de esta experiencia va dirigido a estudiantes de la carrera de Óptica y Optometría. Este año se ha llevado a cabo en la asignatura de "Laboratorio de Optometría" y se pretende hacerlo extensible a la asignatura de "Contactología". Sin embargo, podría ser de utilidad para cualquier área que enseñe a emplear instrumentos con microscopios binoculares, es decir, gran parte de la titulaciones del área de la biomedicina.

\section{Referencias}

CHAUHAN K (1999). “The Slit-lamp and its use”. Optician, 5692 217:24-30.

GARGALLO A, y ARINES J (2014)."Slit-Lamp handling: Learning upgrade with webcam video recordings". Óptica Pura y Aplicada, 47(2):163-167.

GONZÁLEZ-CAVADA J (2015). Atlas de lámpara de hendidura y lentes de contacto. Biomicroscopía ocular. Madrid: Grupo ICM Comunicación.

JONES L, VEYS J y BERTRAND P (1996). "Slit-lamp biomicroscopy - how to expand your routine". Optician, 5550 211:30-32.

PAINTER R (2015). "Slit lamp photography: The basics". Journal of Visual Communication in Medicine, 38(1-2):119-123. 
Mejora en la interpretación de las imágenes proporcionadas por la lámpara de hendidura mediante la visualización $3 D$.

PERCHES S, y REMÓN L (2015). "Slit-Lamp biomicroscopy: Specular refraction and scattering sclero-corneal illumination”. Óptica Pura y Aplicada, 48(2):171-174.

SULLEY A, YOUNG G, LORENZ KO y HUNT C (2013). "Clinical evaluation of fitting toric soft contact lenses to current non-users". Ophthalmic and Physiological Optics, 33(2):94-103.

VEYS J, MEYLER J, DAVIES I (2016). Essential Contact Lens Practice. Slit-lamp Examination. Johnson \& Johnson Medical Limited.

\section{Agradecimientos}

Los autores agradecen a la Universidad de Zaragoza la concesión de un Proyecto de Innovación Docente con código PIIDUZ_18_446 y título: "Acción para la mejora del aprendizaje del uso de la lámpara de hendidura mediante la visualización de imágenes 3D" dentro de la Convocatoria de Innovación Docente 2018-2019. 